\title{
An evaluation of the Daisy II-220 technique for determining in vitro digestibility of animal feeds in comparison with the Minson \& McLeod technique
}

\author{
M. de Figueiredo, A. Mbhele and J. Zondi \\ Dept of Agriculture, KwaZulu-Natal, P Bag X9059, Pietermaritzburg, 3200
}

\section{Introduction}

The digestibility value of a feed is one of the best indicators of nutritive value. In vivo determinations are expensive and time-consuming rendering this technique impractical for routine analyses. In vitro determinations of digestibility using rumen fluid/cellulase have been used extensively in laboratories worldwide. These techniques use individual digestion containers shaken twice daily and a two-stage $48 \mathrm{~h}$ digestion. Due to the individual sample handling, filtration and washing steps performed , the introduction of human error and amount of time spent performing these steps are extremely high. The filter bag technology used in the Daisy apparatus involves enclosing the sample in a filter bag placed in a common rumen fermenter which can digest up to 100 samples at one time (compared with 40 in the conventional systems). This apparatus permits batch processing, removes the filtration step and maintains uniform heating with constant shaking. The Daisy apparatus and procedure used was evaluated against the procedure described by Tilley \& Terry (1963) and subsequently modified by Minson \& McLeod (1972). The two procedures differ from each other in that neutral detergent fibre (NDF) is determined in the rumen digesta (Daisy) instead of a pepsin digestion, The rumen digesta is shaken continuously (Daisy), compared with twice daily and the buffer composition and the rumen fluid:buffer ratio differs from each technique. The evaluation of the Daisy procedure and its comparison with the Minson \& McLeod (M\&M) technique, was done by a series of experiments using eragrotis hay (low digestibility), kikuyu grass (medium digestibility), maize crop and ryegrass (high digestibility).

\section{Material and Methods} litre).

Chemical content of the buffers are shown in Table 1 (numbers in parenthesis represent grams per

Table 1 Composition of buffers A and B.

\begin{tabular}{llll}
\hline & \multicolumn{1}{c}{ Buffer A } & \multicolumn{1}{c}{ Buffer B } \\
Daisy II & \multicolumn{1}{c}{ Minson \& McLeod } & Daisy II & Minson \& McLeod \\
\hline $\mathrm{KH}_{2} \mathrm{PO}_{4}(10)$ & $\mathrm{Na}_{2} \mathrm{CO}_{3}(9.8)$ & $\mathrm{Na}_{2} \mathrm{CO}_{3}(15)$ & $\mathrm{CaCl}_{2} .2 \mathrm{H}_{2} \mathrm{O}(53)$ \\
$\mathrm{MgSO}_{4} .7 \mathrm{H}_{2} \mathrm{O}(0.5)$ & $\mathrm{Na}_{2} \mathrm{HPO}_{4}(3.7)$ & $\mathrm{Na}_{2} \mathrm{~S}_{2} 9 \mathrm{H}_{2} \mathrm{O}(1)$ & \\
$\mathrm{NaCl}(0.5)$ & $\mathrm{Kcl}(0.57)$ & & \\
$\mathrm{CaCl}$ & & \\
Urea $(0.5)$ & $\mathrm{NaCl}(0.47)$ & & \\
\hline
\end{tabular}

Rumen fluid was taken from a fistulated Friesian cow and kept in a thermos bottle preheated with 39 $\mathrm{C}$ water. The rumen inoculum was blended at high speed for $30 \mathrm{~s}$. in a blender container purged with $\mathrm{CO}_{2}$. The blended digesta was filtered through four layers of cheesecloth and continually purged with $\mathrm{CO}_{2}$. A ratio of buffer:rumen fluid (5:1) is used for the Daisy procedure, while a ratio of 4:1 was used in the procedure of Minson \& McLeod. Bags/bottles were weighed and their weight recorded. An amount of $0.25 \mathrm{~g}$ of sample was weighed into the respective containers, bags (Daisy II) and "Purity" bottles (Minson \& McLeod). The buffers were prepared and kept at $39^{\circ} \mathrm{C}$ in a atmosphere of $\mathrm{CO}_{2 . .}$ The buffer/rumen mixture was prepared as above and $1600 \mathrm{ml}$ of the combined solution added to each digestion jar (Daisy II) or $50 \mathrm{ml}$ to each "Purity" bottle. The digestion containers were purged for $30 \mathrm{sec}$., the lids secured and the samples were digested for $48 \mathrm{~h}$. In the Daisy procedure, after incubation, the jars were removed and the fluid drained. The bags were rinsed thoroughly with cold water until the water was clear, using a minimum of agitation. A NDF determination was done on the digesta in the bags to remove microbial debris. In the Minson \& McLeod procedure, $4 \mathrm{ml}$ of the acid solution was added to each "Purity" bottle, followed by $4 \mathrm{ml}$ of pepsin solution. 
After the $48 \mathrm{~h}$ pepsin digestion the acid/pepsin sol. was aspirated and the samples washed and aspirated three times before the bottles with the samples were dried to constant weight.

\section{Results and Discussion}

\section{Experiment 1 (Reproducibility)}

Kikuyu grass (96 replicates) was analysed in the Daisy II apparatus according to the procedure reported above. A good reproducibility was attained shown by the low coefficient of variation $(2.65 \%)$ between jars and within jars (3.92, 2.13, 6.12 and 1.94 for jar No.1, 2, 3, and 4, respectively).

Experiment 2 (Comparison between Daisy technique and M\&M technique)

The Daisy technique gave consistently higher digestibility values than the M\&M technique (71.68 vs.52.16; 95.2 vs $79.12 ; 77.04$ vs $63.44 ; 37.12$ vs 23.60 for Kikuyu, ryegrass, maize and hay, respectively)

Experiment 3 (Comparison between the Daisy buffer and the M\&M)

The digestibility values obtained (66.56 vs $68.96 ; 93.68$ vs $93.84 ; 74.08$ vs 76.56 and 34.12 vs 40.50 for the kikuyu, ryegrass, maize and hay, respectively) when comparing the Daisy buffer with the M\&M buffer, respectively, showed that these buffers can replace each other.

Experiment 4 (Comparison between continuous and twice-daily shaking in the Daisy technique)

The continuous shaking produced significantly higher digestibility results $(71.68$ vs $45.76 ; 95.2$ vs $79.28 ; 77.04$ vs 57.60 and 37.12 vs 21.84 ) than when shaking occurred only twice daily.

\section{Conclusion}

The use of the Daisy II apparatus for the in vitro digestibility determination using the M\&M buffer was found to be easy and reproducible. However, a considerable difference in the dry matter digestibility values was found between the two procedures.

\section{References}

Minson, D.J. \& Mcleod, M.N., 1972. Division of Tropical Pastures Technical Paper No. 8, Commonwealth Scientific and Industrial Research Organization, Australia.

Tilley, J.M.A. \& Terry, R.A., 1963. J. Brit. Grassl. Soc. 18, 104. 